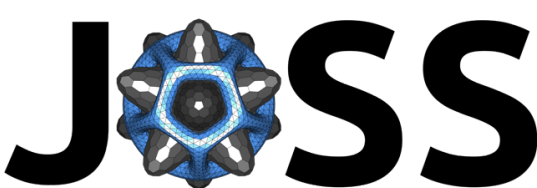

The Journal of Open Source Software

DOI: $10.21105 /$ joss. 02782

\title{
hectorui: A web-based interactive scenario builder and visualization application for the Hector climate model
}

\author{
Jason Evanoff ${ }^{1}$, Chris R. Vernon ${ }^{1}$, Stephanie Waldhoff ${ }^{1}$, Abigail \\ Snyder ${ }^{1}$, and Corinne Hartin ${ }^{1}$
}

1 Joint Global Change Research Institute, Pacific Northwest National Laboratory, College Park, MD, USA

\section{Software}

- Review ¿

- Repository $\boldsymbol{c}^{\boldsymbol{T}}$

\section{Statement of need}

- Archive [

Editor: Kristen Thyng ¿ Reviewers:

- @marvinjonathon

- Otscheypidi

Submitted: 08 October 2020 Published: 11 December 2020

\section{License}

Authors of papers retain copyright and release the work under a Creative Commons Attribution 4.0 International License (CC BY 4.0).

In a world of increasingly online, distributed, and diverse interdisciplinary research, there is a need to provide accessible and user-friendly interactive visualization tools that elucidate complex models and their output products. hectorui is an R Shiny web interface built to enhance the user experience for the simple global climate model Hector (Hartin et al., 2015), originally designed in $\mathrm{C}++$ and later extended with an $\mathrm{R}$ interface. Before hectorui, Hector only had a command line-based interface available which requires fluency in $\mathrm{C}++$ or $\mathrm{R}$ and a full understanding of Hector's parameter space to run the model and create output. hectorui provides a fast, efficient solution that makes the model more accessible to a broader user base and offers enhanced functionality (Figure 1 ). This implementation allows users that may not be fluent in a programming language to interactively explore model scenarios and outputs in an easy to use, guided point and click interface.

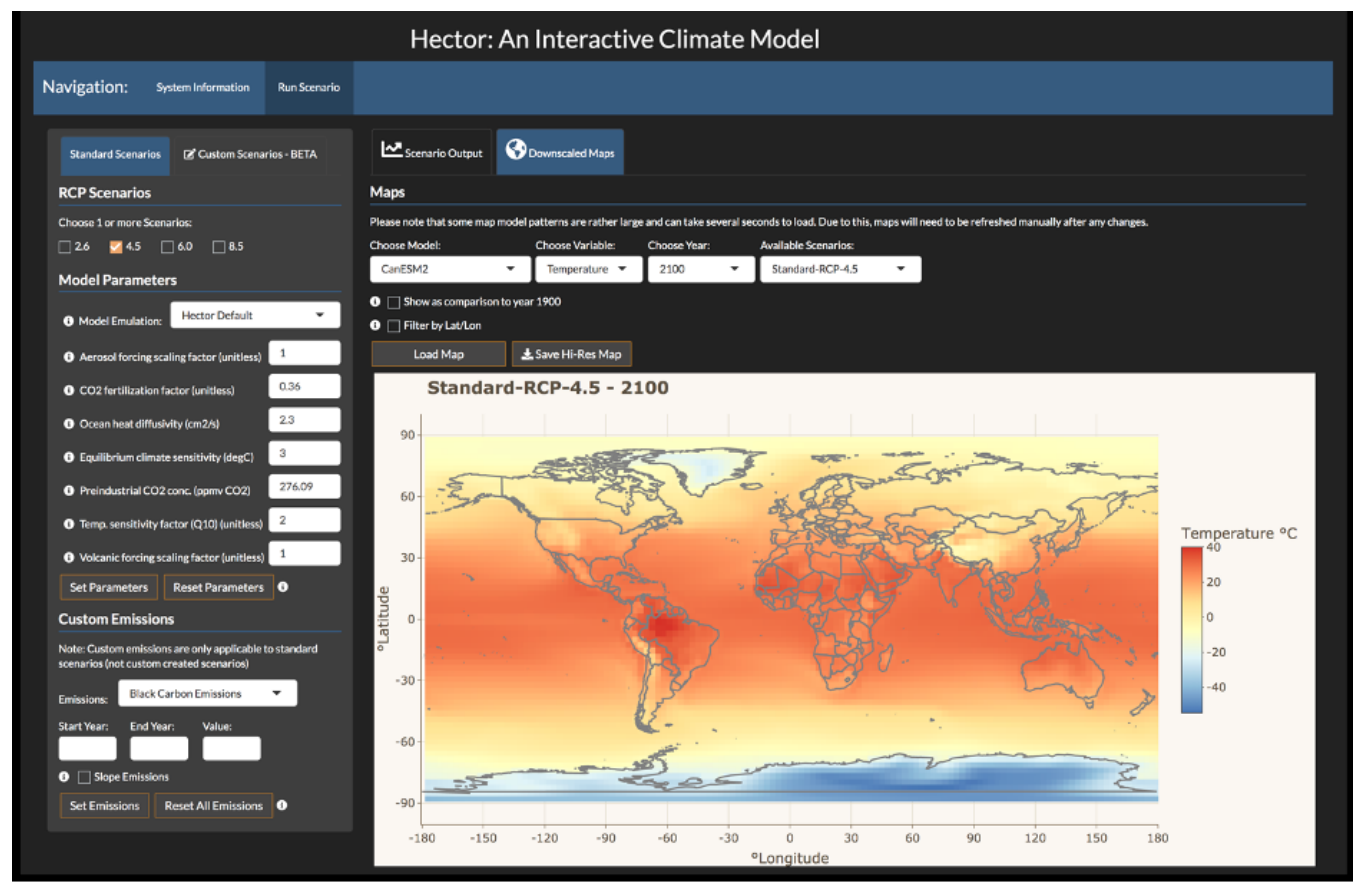

Figure 1: The map scenario interface to hectorui that allows the user to parameterize inputs and visualize run outputs interactively.

Evanoff et al., (2020). hectorui: A web-based interactive scenario builder and visualization application for the Hector climate model. Journal 1 of Open Source Software, 5(56), 2782. https://doi.org/10.21105/joss.02782 


\section{Supporting software}

The hectorui application was built in R Studio using the Shiny package. Shiny is a package for $\mathrm{R}$ that makes it easy to build and deploy interactive web apps straight from $\mathrm{R}$ (Chang et al., 2020). The built in components provide easy to use controls and layout functionality for building web applications without writing HTML.

The supporting software for hectorui is Hector, an open source, object-oriented, simple global climate carbon-cycle model. It runs essentially instantaneously while still representing the most critical global scale earth system processes and is one of a class of models heavily used for emulating complex climate models and uncertainty analyses (Hartin et al., 2016). Hector is also an input component for the Global Change Analysis Model (GCAM; Calvin et al., 2019). To run the model, a Hector core object is instantiated from an input file that contains a time series of greenhouse gas emissions. Hector comes equipped with input files, or scenarios, based on the Representative Concentration Pathways (RCP) 2.6 (Van Vuuren et al., 2011), 4.5 (Clarke et al., 2007; Thomson et al., 2011), 6.0 (Fujino et al., 2006), and 8.5 (Riahi et al., 2007, 2011). These scenarios were developed to cover the full range of potential emissions scenarios and were designed to meet research needs, such as output from human-Earth systems and sectoral models, impact analysis, and policy relevant research.

\section{Summary}

hectorui provides the full functionality of Hector in a user-friendly web interface that can create Hector cores on demand to view any number of scenarios in parallel. Graphs of up to four output variables can be viewed simultaneously with each scenario represented as a time series. In addition to supporting Hector's full functionality, the following describes some new capabilities that the hectorui offers. First, the user can configure Hector's model input parameters to have the model emulate other well-known earth system models. This allows the user to seamlessly switch between models and see the changes reflected in the output. Another new feature provided are downscaled, gridded global maps of both temperature and precipitation that are dynamically generated from pattern files based on Hector and the other earth system models (Snyder et al., 2019). Lastly, in addition to the included canonical RCP scenarios the user can upload a set of custom emissions and run the model using these emissions to generate new time series results tailored to their specific research needs.

The ability to visualize and explore the model scenarios and data output for Hector allows both a broader user base to access Hector and the ability to rapidly explore scenarios and output. By creating user-friendly software that is simple to use which offers a generous set of predefined functionality, hectorui enhances Hector's accessibility and equips the end user with the capability to focus on discovery and analysis instead of data processing, transformation, and time-consuming graph and chart development.

hectorui can be accessed via the web at the public domain https://jgcri.shinyapps.io/ HectorUI/ or it can be installed and run locally as a standalone package (see https://github. $\mathrm{com} / \mathrm{JGCRI} /$ hectorui to clone or fork for collaborative purposes). We provide an $\mathrm{R}$ vignette step-by-step tutorial for users to get started with hectorui which is accessible here: Tutorial.

\section{Acknowledgements}

This research was supported in part by the U.S. Department of Energy, Office of Science, as part of research in MultiSector Dynamics, Earth and Environmental System Modeling Program. The Pacific Northwest National Laboratory is operated for DOE by Battelle Memorial

Evanoff et al., (2020). hectorui: A web-based interactive scenario builder and visualization application for the Hector climate model. Journal 2 of Open Source Software, 5(56), 2782. https://doi.org/10.21105/joss.02782 
Institute under contract DE-AC05-76RL01830. The authors also received support for this research through the U.S. Environmental Protection Agency, under Interagency Agreement DW08992459801. The views and opinions expressed in this paper are those of the authors alone.

\section{References}

Calvin, K., Patel, P., Clarke, L., Asrar, G., Bond-Lamberty, B., Cui, R. Y., Di Vittorio, A., Dorheim, K., Edmonds, J., Hartin, C., \& others. (2019). GCAM v5.1: Representing the linkages between energy, water, land, climate, and economic systems. Geoscientific Model Development (Online), 12(PNNL-SA-137098). https://doi.org/10.5194/ gmd-12-677-2019

Chang, W., Cheng, J., Allaire, J., Xie, Y., \& McPherson, J. (2020). Shiny: Web application framework for $R$. https://CRAN.R-project.org/package=shiny

Clarke, L., Edmonds, J., Jacoby, H., Pitcher, H., Reilly, J., \& Richels, R. (2007). Scenarios of greenhouse gas emissions and atmospheric concentrations.

Fujino, J., Nair, R., Kainuma, M., Masui, T., \& Matsuoka, Y. (2006). Multi-gas mitigation analysis on stabilization scenarios using AIM global model. The Energy Journal, Special Issue\# 3. https://doi.org/10.5547/ISSN0195-6574-EJ-VoISI2006-NoSI3-17

Hartin, C. A., Bond-Lamberty, B., Patel, P., \& Mundra, A. (2016). Ocean acidification over the next three centuries using a simple global climate carbon-cycle model: Projections and sensitivities. Biogeosciences, 13(15), 4329-4342. https://doi.org/10.5194/ bg-13-4329-2016

Hartin, C. A., Patel, P., Schwarber, A., Link, R. P., \& Bond-Lamberty, B. P. (2015). A simple object-oriented and open-source model for scientific and policy analyses of the global climate system - Hector v1.0. Geoscientific Model Development, 8(4), 939-955. https://doi.org/10.5194/gmd-8-939-2015

Riahi, K., Grübler, A., \& Nakicenovic, N. (2007). Scenarios of long-term socio-economic and environmental development under climate stabilization. Technological Forecasting and Social Change, 74(7), 887-935. https://doi.org/10.1016/j.techfore.2006.05.026

Riahi, K., Krey, V., Rao, S., Chirkov, V., Fischer, G., Kolp, P., Kindermann, G., Nakicenovic, N., \& Rafai, P. (2011). RCP-8.5: Exploring the consequence of high emission trajectories. Climatic Change. Doi, 10, 1007. https://doi.org/10.1007/s10584-011-0149-y

Snyder, A., Link, R., Dorheim, K., Kravitz, B., Bond-Lamberty, B., \& Hartin, C. (2019). Joint emulation of Earth system model temperature-precipitation realizations with internal variability and space-time and cross-variable correlation: Fldgen v2.0 software description. Plos One, 14(10), e0223542. https://doi.org/10.1371/journal.pone.0223542

Thomson, A. M., Calvin, K. V., Smith, S. J., Kyle, G. P., Volke, A., Patel, P., DelgadoArias, S., Bond-Lamberty, B., Wise, M. A., Clarke, L. E., \& others. (2011). RCP4.5: A pathway for stabilization of radiative forcing by 2100. Climatic Change, 109(1-2), 77. https://doi.org/10.1007/s10584-011-0151-4

Van Vuuren, D. P., Stehfest, E., Elzen, M. G. den, Kram, T., Vliet, J. van, Deetman, S., Isaac, M., Goldewijk, K. K., Hof, A., Beltran, A. M., \& others. (2011). RCP2.6: Exploring the possibility to keep global mean temperature increase below $2^{\circ} \mathrm{C}$. Climatic Change, $109(1-$ 2), 95. https://doi.org/10.1007/s10584-011-0152-3 